\title{
Study the Effect of Alloying of Mg \\ on the Structure and Properties \\ of Car Wheels Produced of AK12 Alloy
}

Vitaly R. Abalymov*a, b, Juriy A. Kleymenov ${ }^{a}$, Tatiana N. Drozdovab Nina V. Okladnikova ${ }^{c}$ and Vladimir P. Zhereb ${ }^{\mathrm{b}}$

${ }^{a} L t d . \ll F M P « S K A D »$

1b/1 Zavodskaya Str., Divnogorsk, 660121, Russia

${ }^{b}$ Siberian Federal University

79 Svobodny Krasnoyarsk, 660041, Russia

${ }^{c} L t d . \ll F P P$ «SEGAL»

103 Pogranichnikov Str., bld. 4, Krasnoyarsk, 660111, Russia

Received 10.02.2015, received in revised form 17.09.2015, accepted 04.10.2015

In this article we examine the effect of alloying of magnesium on the structure, mechanical properties and resistance to fracture during bench test of car wheels produced of AK12 alloy to improve properties. Mounted interconnection between the of $\mathrm{Mg}$ content, structure and properties car wheels of the investigated alloy. Were optimized chemical composition of the alloy, which allows to achieve higher qualities.

Keywords: Alloying, microstructure, founding, strength, plasticity, strengthening.

DOI: 10.17516/1999-494X-2015-8-7-948-956.

(C) Siberian Federal University. All rights reserved

* Corresponding author E-mail address: AbalymovVR@yandex.ru 


\title{
Исследование влияния легирования магнием \\ сплава АК12 на структуру \\ и свойства автомобильных колес
}

\author{
В.Р. Абалымов ${ }^{\text {a, }}$, Ю.А. Клейменов \\ Т.Н. Дроздова ${ }^{\sigma}$, Н.В. Окладникова ${ }^{\text {, }}$ В.П. Жереб \\ ${ }^{a}$ ООО ЛМЗ «СКАД》 \\ Россия, 660121, Дивногорск, Заводская, 1б/1 \\ ${ }^{6}$ Сибирский федеральный университет \\ Россия, 660041, Красноярск, пр. Свободный, 79 \\ ${ }^{6}$ ООО ЛПЗ «СЕГАЛ»
}

Россия, 660121, Красноярск, Пограничников, 103

\begin{abstract}
В статье рассмотрено влияние легирования магнием на структуру, механические свойства и устойчивость к разрушению при стендовых испытаниях автомобильных дисков колес из сплава АК12 для повышения свойств. Установлены взаимосвязи между концентрацией магния, структурой и свойствами дисков колес из исследуемого сплава. Выбран наиболее оптимальный химический состав сплава, позволяющий достигать повышенных свойств.
\end{abstract}

Ключевые слова: легирование, микроструктура, отливка, прочность, пластичность, упрочнение.

\section{Введение}

В настоящее время при производстве автомобильных легкосплавных колес используют преимущественно литейные алюминиевые сплавы на основе системы Al-Si. Как известно, для всех литейных сплавов основными являются такие характеристики, как высокая жидкотекучесть, способствующая оптимальному заполнению литейной формы, малая склонность к образованию усадочных и газовых пустот, трещин, раковин. Сплав АК12 имеет наиболее высокие литейные свойства.

Качество литых автомобильных дисковых колес в нашей стране должно удовлетворять требованиям ТР № 720, правилам ЕЭК ООН № 124, ГОСТ Р 50511-93 и ГОСТ Р 52390-2005 [1-4]. В этих документах содержатся основные требования к колесам, в том числе регламентирован уровень механических свойств: $\sigma_{\mathrm{B}} \geq 160 \mathrm{MПа;} \sigma_{0,2} \geq 80 \mathrm{MПа;} \delta \geq 5 \%$, НВ 45-60.

Прочностные характеристики литейных сплавов повышают за счёт улучшения структуры, путем введения в сплав модифицирующих элементов в виде лигатур AlTi5B1 и AlSr10. Также упрочнение при литье под низким давлением достигается за счет образования твердых растворов, которые в условиях неравновесной кристаллизации слитков и отливок часто оказываются аномально пересыщенными. Эти растворы распадаются при последующих технологических нагревах, а образовавшиеся вторичные алюминиды переходных металлов сами по себе способствуют некоторому упрочнению, особенно при повышенных температурах [5].

Одним из основных легирующих элементов в силуминах является магний. Магний способствует повышению прочности и твердости, но снижает в той или иной степени показатели пластичности силуминов. Влияние магния связано одновременно с изменением

$$
-949-
$$


нескольких структурных факторов: с увеличением доли магния повышается насыщенность алюминиевого раствора, образуется большее количество дополнительных избыточных фаз кристаллизационного происхождения и вторичных их выделений, становится грубее структура кремниевой эвтектики [6]. Магний - один из наиболее распространенных легирующих компонентов, вводимых в состав силуминов; взаимодействуя с кремнием, он образует интерметаллическое соединение $\mathrm{Mg}_{2} \mathrm{Si}$ ( $\beta$-фаза) с высокой микротвердостью [7]. Наряду с положительным влиянием на прочностные характеристики магнийсодержащие фазы отрицательно влияют на показатели пластичности как в литом состоянии, так и после упрочняющей термической обработки [8].

В настоящей работе проведена оценка возможности повышения прочностных характеристик сплава АК12 за счет легирования его магнием.

\section{Методика проведения исследования}

Шихтовыми материалами в условиях литейно-механического завода «СКАД» служили мелкогабаритная чушка (МГЧ) первичного алюминия производства ОАО «РУСАЛ», МГЧ магния Мг90 производства ОАО «ВСМПО АВИСМА» и отходы собственного производства. В качестве модификаторов применялась прутковая лигатура AlTi5B1 для модифицирования алюминиевого твердого раствора и AlSr10 для модифицирования эвтектики.

На первом этапе работы по исследованию влияния магния на свойства сплава АК12 в лабораторных условиях были получены кокильные отливки диаметром 25, длиной 120 мм. Далее в промышленных условиях были приготовлены опытные плавки с различным содержанием магния $(0,129-0,318$ \%) и отлиты модели дисковых колес методом литья под низким давлением.

Механические свойства образцов определяли по результатам испытаний на одноосное растяжение на универсальной испытательной машине TesT Winner в соответствии с ГОСТ 1497-84 [9]. Испытания на твердость проводили на приборе 2109ТБ по ГОСТ 9012-59 [10]. Образцы для испытаний механических свойств колес выбирали из разных зон колеса в соответствии с Правилами 124 ЕЭК ООН [2].

Металлографические исследования осуществляли с помощью оптического микроскопа Axio Observer.A1m (Carl Zeiss) и стереографического микроскопа SZ61 (Olympus). Макроструктуру исследовали на темплетах, в сечение которых попадали основные зоны колеса. Для исследования микроструктуры изготавливали микрошлифы, вырезанные из спиц колес. Количественный анализ микроструктуры проводили в программе ImageExpert Pro 3.

Стендовые испытания дисковых колес осуществляли по ГОСТ Р 50511-93 [3] и Правилам 124 ЕЭК ООН [2] на установках: на изгиб при кручении - Leonardo Bending Machine 10 KHm FR12 и Borli MK 818 (отбирали по два колеса каждой плавки, колеса должны пройти 200000

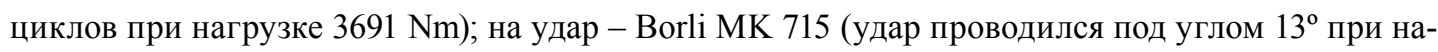
грузке 750 кг).

\section{Результаты исследования и их обсуждение}

Влияние магния на механические свойства опытных отливок. Для предварительной оценки влияния магния на свойства сплава АК12 были отлиты в металлическую изложницу опытные 
отливки. Химический состав опытных отливок с разным содержанием магния приведен в табл. 1. Исследуемые плавки по всем элементам удовлетворяют требованиям ГОСТ 1583-93 [11], за исключением концентрации магния, который намеренно вводили в сплав АК12 в различном количестве для оценки его влияния на свойства отливок. В опытных отливках магний изменялся в интервале $0,06-0,42 \%$.

Анализ микроструктуры опытных отливок в исследуемом интервале концентрации магния не выявил фазы $\mathrm{Mg}_{2} \mathrm{Si}$; это означает, что весь магний растворяется в алюминиевом твердом растворе.

Зависимость механических свойств от концентрации магния в опытных отливках приведена на рис. 1. Механические свойства всех отливок удовлетворяют требованиям ГОСТ 1583-93 [11].

При повышении концентрации магния в отливках предел прочности возрастает на $20 \mathrm{MПа}$ и существенно увеличивается предел текучести - на 40 МПа, твердость сплава линейно повышается на 9 НВ. Увеличение концентрации магния в исследуемом интервале приводит к снижению пластических характеристик в 1,5 раза.

Таблица 1. Химический состав опытных отливок

\begin{tabular}{|c|c|c|c|c|c|c|c|c|c|c|c|c|}
\hline \multirow{2}{*}{$\begin{array}{c}\text { Номер } \\
\text { отливки }\end{array}$} & \multicolumn{10}{|c|}{ Массовая доля элементов, \% } \\
\cline { 2 - 15 } & $\mathrm{Si}$ & $\mathrm{Mg}$ & $\mathrm{Ti}$ & $\mathrm{Sr}$ & $\mathrm{Mn}$ & $\mathrm{Cu}$ & $\mathrm{Ni}$ & $\mathrm{Zn}$ & $\mathrm{Fe}$ & $\mathrm{B}$ & $\mathrm{Cr}$ & $\mathrm{Zr}$ \\
\hline 1 & 10,34 & 0,064 & 0,081 & 0,017 & 0,101 & 0,0089 & 0,0067 & 0,011 & 0,146 & 0,0017 & 0,001 & 0,002 \\
\hline 2 & 10,26 & 0,151 & 0,081 & 0,018 & 0,105 & 0,0017 & 0,0065 & 0,002 & 0,142 & 0,0025 & 0,001 & 0,002 \\
\hline 3 & 10,18 & 0,264 & 0,085 & 0,017 & 0,105 & 0,0015 & 0,0063 & 0,002 & 0,14 & 0,0017 & 0,001 & 0,002 \\
\hline 4 & 10,27 & 0,366 & 0,081 & 0,018 & 0,109 & 0,0016 & 0,0062 & 0,002 & 0,145 & 0,0021 & 0,001 & 0,002 \\
\hline 5 & 10,29 & 0,423 & 0,080 & 0,015 & 0,104 & 0,0016 & 0,0063 & 0,002 & 0,148 & 0,0011 & 0,001 & 0,002 \\
\hline & \multicolumn{10}{|c|}{ Массовая доля примесей, \%, не более } \\
\hline ГОСТ 1583-93 & $10-13$ & 0,10 & 0,10 & - & 0,5 & 0,6 & - & 0,3 & 1,0 & - & - & 0,1 \\
\hline
\end{tabular}

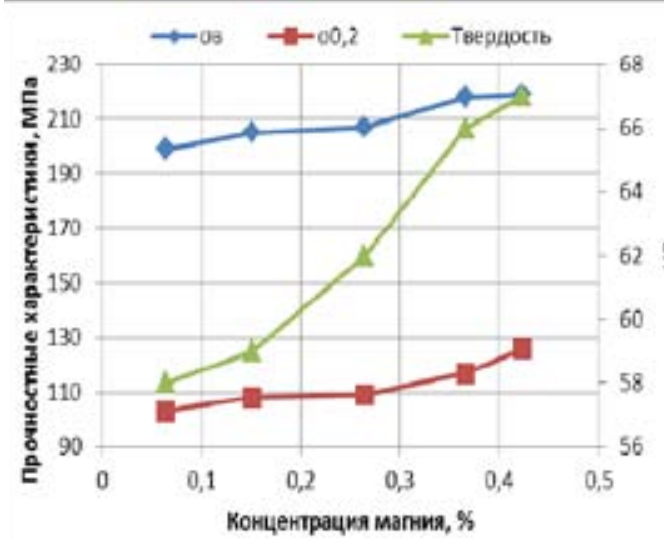

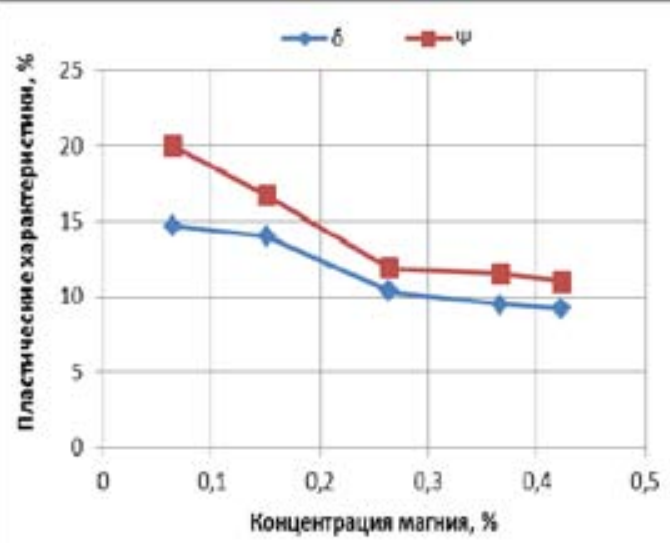

6

Рис. 1. Механические свойства опытных отливок: а - прочность; б - пластичность

$$
-951-
$$


Анализ результатов изменения механических свойств показал, что в опытных отливках при повышении концентрации магния прочностные свойства увеличиваются за счет повышения степени легированности твердого раствора магнием, обеспечивается твердорастворное упрочнение и приводит к снижению пластических характеристик сплава АК12.

Влияние магния на структуру и свойства колес. Опытные партии колес были получены из сплава АК12 с содержанием кремния на верхнем пределе требований ТИ 1-1-2012 - 11,2-11,35 \% и концентрацией магния 0,13-0,32 \%.

Исследование микроструктуры. Для достижения максимальных механических свойств следует стремиться к получению минимальных размеров структурных составляющих с наиболее правильной формой. В сплавах системы Al-Si получению мелкокристаллической структуры способствуют модификаторы AlTi5B1 и AlSr10. Дополнительно измельчение дендритной ячейки и кристаллов кремния можно получить при повышении скорости охлаждения.

Для исследования микроструктуры образцы были вырезаны из спиц, так как они являются наиболее конструктивно нагруженной зоной. Характерная микроструктура спицы колеса состоит из дисперсной эвтектики $(\alpha+\mathrm{Si})$ и дендритов алюминиевого твердого раствора (рис. $2 a$ ). Магний в силуминах образует фазу $\mathrm{Mg}_{2} \mathrm{Si}$, которая выделяется в форме иероглифов. В структуре опытных отливок колес присутствует фаза $\mathrm{Mg}_{2} \mathrm{Si}$, а также железосодержащие фазы $\beta\left(\mathrm{FeSiAl}_{5}\right.$ ) размерами 30-75 мкм (рис. 2б). Размер фазы $\mathrm{Mg}_{2} \mathrm{Si}$ увеличивается с повышением концентрации магния в сплаве АК12 с 8×14 до 95×73 мкм. Полученные результаты согласуются с данными, приведенными в работе [12].

Количественный анализ микроструктуры спиц исследуемых колес выявил, что средний размер дендритной ячейки в спице составляет 22-26 мкм. С увеличением содержания магния в сплаве АК12 от 0,13 до $0,32 \%$ возрастает объемная доля немодифицированной эвтектики с 1,4 до $3,4 \%$ (рис. 3 ).

Влияние содержания магния на колеса и показатели сферичности кристаллов эвтектического кремния представлены на рис. 3. Основным параметром сферичности является формфактор; чем ближе его значение к единице, тем более округлую форму имеет объект. В сплаве

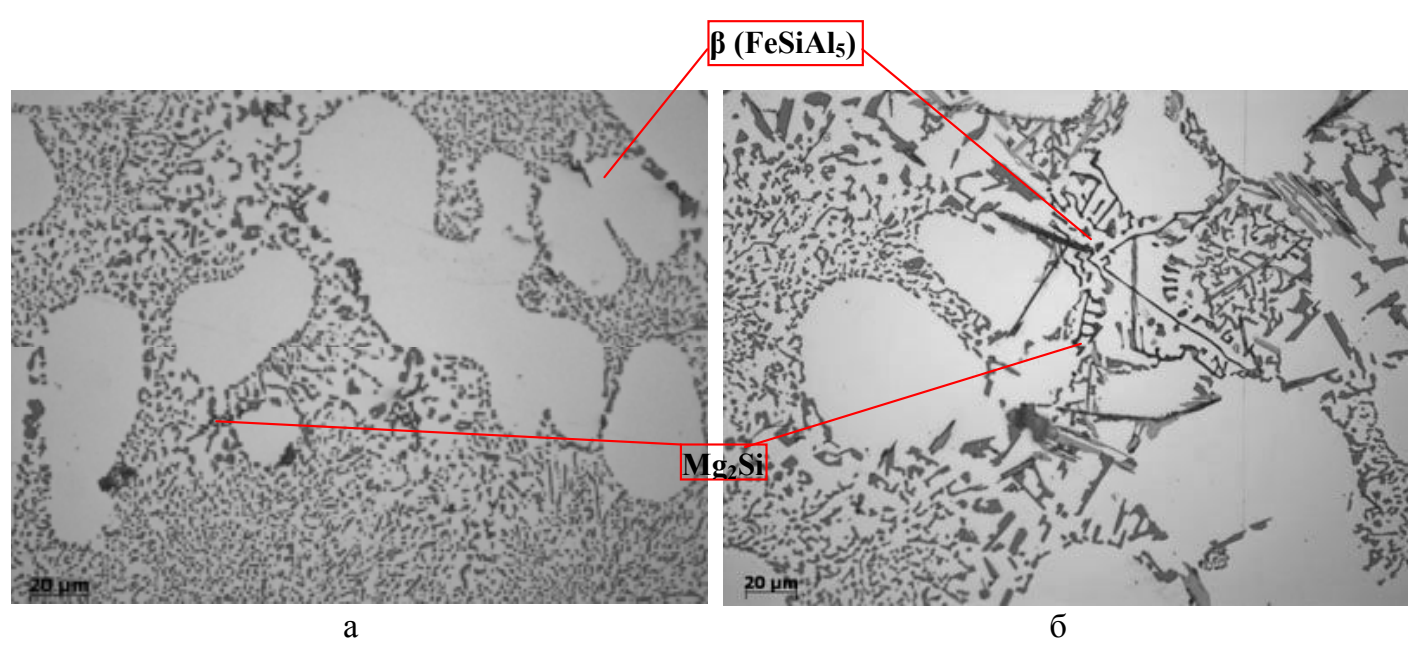

Рис. 2. Микроструктура спицы из сплава АК12: a - 0,13 \% Mg; б - 0,32 \% Mg 
с $0,13 \% \mathrm{Mg}$ кристаллы эвтектического кремния компактные, с увеличением концентрации магния они приобретает более вытянутую форму, а их размеры увеличиваются.

Механические свойства. Образцы для измерения механических свойств были вырезаны из зон: внешняя бортовая закраина, спица и ступица. Измерение твердости проводилось на образцах, вырезанных из ступицы.

По показателям механических свойств исследуемые зоны из сплавов с концентрацией магния 0,13-0,17 \% соответствуют требованиям ГОСТ Р 50511-93 (рис. 4, 5).

Из графиков, приведенных на рис. 4, видно, что с увеличением содержания магния предел прочности уменьшается на 9-16 МПа, наиболее резкое снижение наблюдается при концентрации магния более $0,25 \%$. Это связано с тем, что увеличивается размер частиц эвтектического кремния и объемная доля немодифицированной эвтектики. Условный предел текучести с повышением концентрации магния показывает незначительный линейный рост на 8 МПа, что обусловлено упрочнением $\alpha$-твердого раствора.

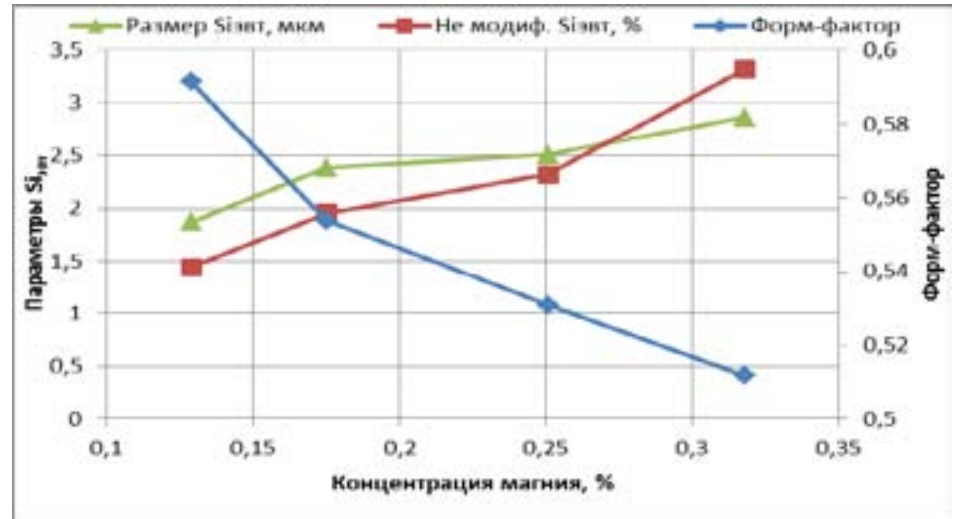

Рис. 3. Количественные параметры эвтектического Si в структуре опытных колес

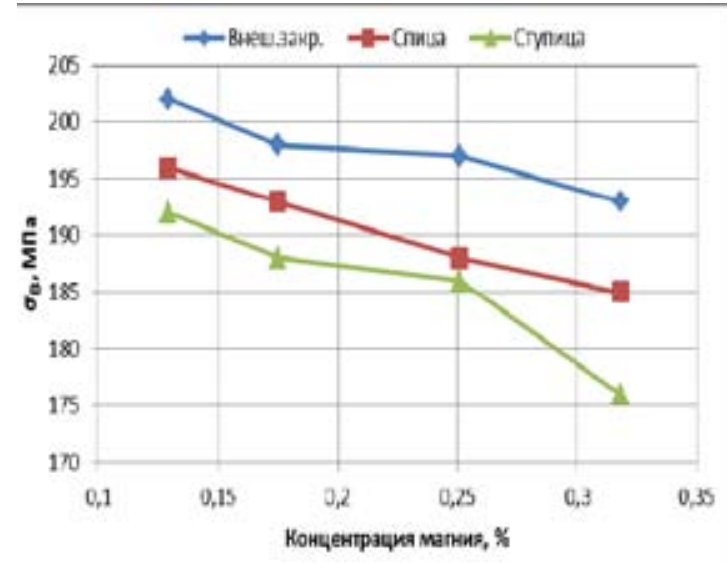

a

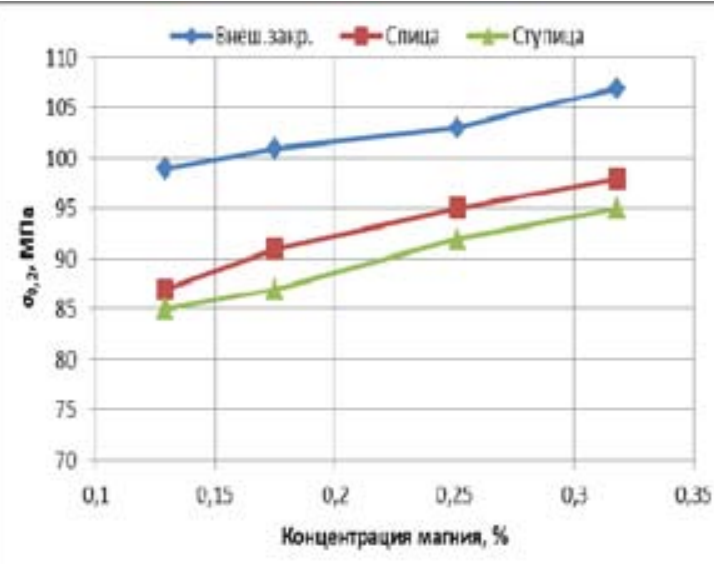

6

Рис. 4. Зависимость прочностных характеристик от концентрации магния: а - предел прочности; б - предел текучести 


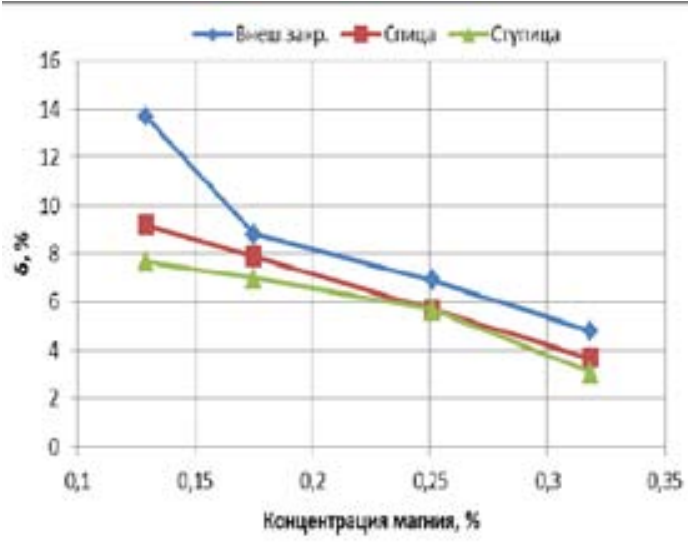

a

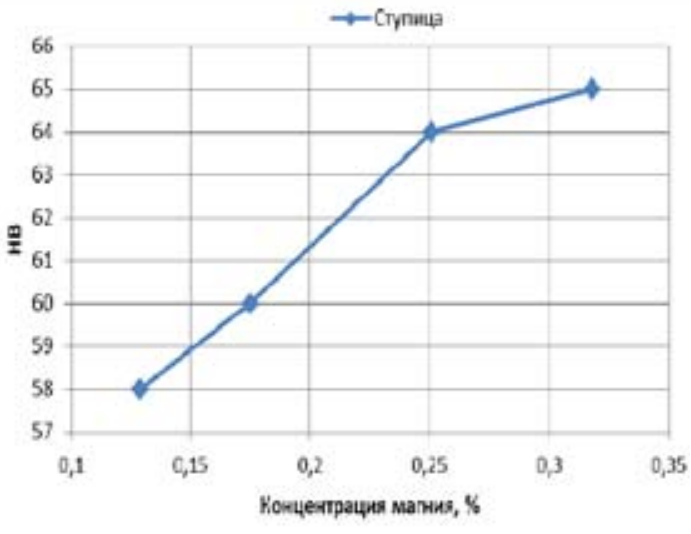

б

Рис. 5. Зависимость механических свойств от концентрации магния: а - относительное удлинение; б- твердость

Известно, что увеличение содержания магния оказывает отрицательное влияние на показатели пластичности [13], что подтверждают результаты, представленные на рис. 5. Твердость с увеличением содержания магния повышается.

Твердость ступицы из сплавов с содержанием $0,25-0,32 \% \mathrm{Mg}$ находится выше требуемого предела, относительное удлинение спицы и ступицы из сплава с $0,32 \% \mathrm{Mg}$ не удовлетворяет требованиям.

Стендовые испытания. Исследуемые колеса, полученные из сплава АК12, кроме колес с $0,32 \% \mathrm{Mg}$, показали положительные результаты после испытания на удар под углом $13^{\circ}$. Внешний вид разрушенного колеса с $0,32 \% \mathrm{Mg}$ после испытания на удар представлен на рис. 6 .

Все колеса прошли испытания на изгиб с вращением без образования трещин. Результаты стендовых испытаний приведены в табл. 2.

Полученные результаты свидетельствуют о том, что все колеса, за исключением колес с содержанием магния $0,32 \%$, имеют достаточный запас устойчивости конструкции к разрушению. Снижение предела прочности и относительного удлинения в сплаве $\mathrm{AK} 12$ с 0,32 \% Mg привело к снижению сопротивления конструкции к испытаниям на удар.

\section{Выводы}

1. Увеличение концентрации магния от 0,06 до 0,42 \% в исследуемых опытных кокильных отливках из сплава АК12 привело к росту прочностных свойств и снижению пластичности за счет упрочнения твердого раствора магнием.

2. Установлено, что в дисковых колесах, отлитых под низким давлением, с увеличением концентрации магния в сплаве АК12 наблюдается увеличение размеров кристаллов эвтектического кремния и объемной доли немодифицированной эвтектики, что сопровождается снижением прочностных и пластических свойств. С ростом концентрации магния в алюминиевом твердом растворе увеличивается предел текучести и твердость сплава AK12. 


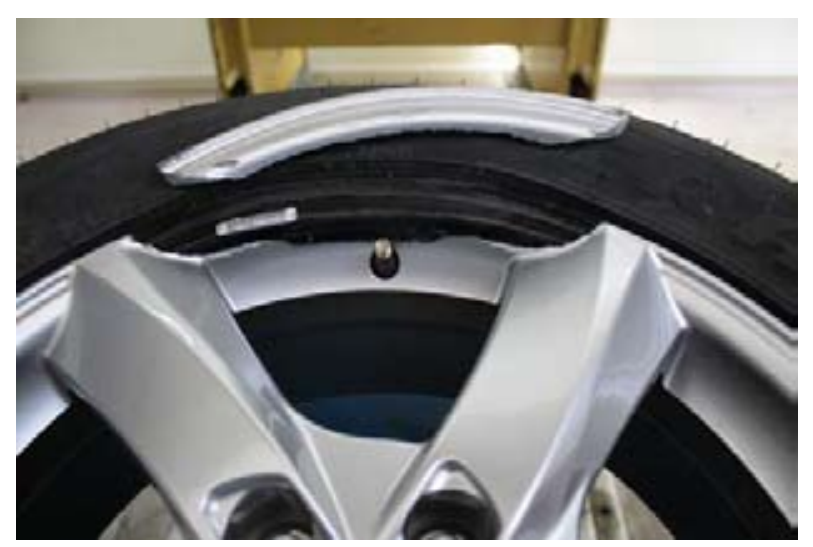

Рис. 6. Колесо после испытания на удар

Таблица 2. Результаты испытаний

\begin{tabular}{|c|c|c|c|}
\hline \multirow{2}{*}{$\begin{array}{c}\text { № опытной } \\
\text { партии }\end{array}$} & $\begin{array}{c}\text { Концентрация } \\
\text { Мg, \% }\end{array}$ & Испытания на удар под углом 13 & Испытания на изгиб \\
\cline { 3 - 4 } & 0,129 & Нагрузка, кг & $\begin{array}{c}\text { Нагрузка, Nm / } \\
\text { Количество циклов }\end{array}$ \\
\hline 1 & 0,175 & 750 & $3691 / 200.000$ \\
\hline 2 & 0,251 & 750 & $3691 / 200.000$ \\
\hline 3 & 0,318 & 750 & $3691 / 200.000$ \\
\hline 4 & $750-$ не прошло & $3691 / 200.000$ \\
\hline
\end{tabular}

3. Легирование сплава АК12 магнием в количестве 0,13-0,17 \% позволяет увеличить запас предела текучести относительно ГОСТ Р 50511-93, при этом сохраняется предел прочности и относительное удлинение на достаточно высоком уровне. Такое сочетание свойств дает конструкции при эксплуатации повышенный запас устойчивости к разрушению. Концентрация магния выше 0,25 \% в сплаве АК12 резко снижает механические и эксплуатационные свойства.

\section{Список литературы}

[1] Технический регламент «О безопасности колесных транспортных средств», утвержденный постановлением Правительства РФ от 10 сентября 2009 г. № 720.

[2] Правила ЕЭК ООН № 124 «Единообразные предписания, касающиеся официального утверждения колес для легковых автомобилей и их прицепов».

[3] ГОСТ Р 50511-93 «Колеса из легких сплавов для пневматических шин».

[4] ГОСТ Р 52390-2005 «Транспортные средства. Колеса дисковые. Технические требования и методы испытания».

[5] Белов Н.А., Савченко С.В., Хван А.В. Фазовый состав и структура силуминов: Справочное издание. М.: МИСИС, 2008. 283 с.

[6] Строганов Г.Б., Ротенберг В.А., Гершман Г.Б. Сплавы алюминия с кремнием. М.: Металлургия, 1977. 272 с.

$$
-955-
$$


[7] Золоторевский В.С., Белов Н.А. Металловедение литейных алюминиевых сплавов. М.: МИСиС, 2005. $376 \mathrm{c.}$

[8] Мондольфо Л.Ф. Структура и свойства алюминиевых сплавов: пер. с англ. М.: Металлургия, 1979.640 с.

[9] ГОСТ 1497-84 «Металлы. Методы испытаний на растяжение».

[10] ГОСТ 9012-59 «Металлы. Методы измерения твердости по Бринеллю».

[11] ГОСТ 1583-93 «Сплавы алюминиевые литейные. Технические условия»

[12] Moustafa M.A., Samuel F.H., Doty H.W. // Materials Science Forum. 2004. Vol. 467470. P. 399.

[13] Белов Н.А. Фазовый состав промышленных и перспективных алюминиевых сплавов. М.: МИСиС, 2010. 511 с. 